\title{
A imagem de Lyon nos guias de viagem (I900-I950): uma abordagem geo-histórica das representações urbanas
}

[ The image of Lyon in travel guides (I900-I950): a geo-historical approach of urban representations

\section{Damien Petermann ${ }^{\mathrm{I}}$}

Texto traduzido do francês por Vanessa Moura de Lacerda Teixeira, com revisão de Eliane Kuvasney.

\begin{abstract}
RESUMO • O guia de viagem impresso é de grande importância para o estudo da imagem da cidade. Através de um corpus contendo quatro coleções de guias, esta pesquisa se interessa pelos meios de construção e evolução da imagem turística de Lyon na primeira metade do século XX. A evolução das representações espaciais lionesas ao longo do tempo pode ser analisada através da busca e da identificação precisas das mudanças no discurso turístico dos guias, principalmente o aparecimento e o desaparecimento de objetos de uma edição a outra. As informações espaciais extraídas dos guias do corpus são integradas num Sistema de Informações Geográficas - SIG, o que permite realizar diferentes tratamentos e cruzamentos de dados. É possível, por exemplo, espacializar os itinerários de visita presentes nos guias. PALAVRAS-CHAVE • Lyon; guia de viagem; imagem
\end{abstract}

da cidade; geo-história; século XX. • ABSTRACT - Printed travel guide is of great interest to study the image of the city. This research is concerned with the modes of construction and the evolution of the touristic image of Lyon in the first half of the $20^{\text {th }}$ century, through a corpus of four collections of travel guides. The evolution of the representations of Lyon urban space can be followed over time by tracking changes in the touristic discourse, like appearance and disappearance of objects between the editions. Extracting spatial information from the guides of the corpus and entering it into a Geographic Information System - GIS makes it possible to conduct various treatments and analyses. For example, it is possible to spatialize the walking tours listed in travel guides. - KEYWORDS • Lyon; travel guidebooks; image of the city; geo-history; $\mathrm{XX}^{\text {th }}$ century.

Recebido em 5 de abril de 2016

Aprovado em 30 de novembro de 2016

PETERMANN, Damien. A imagem de Lyon nos guias de viagem (I900-I950): uma abordagem geo-histórica das representações urbanas. Revista do Instituto de Estudos Brasileiros, Brasil, n. 65 , p. I20-I44, dez. 2016.

DOI: http://dx.doi.org/Io.II6o6/issn.23I6-90IX.voi65pI20-I44

I Universidade Jean Moulin Lyon 3 (Lyon, França). 
O objetivo deste artigo é mostrar a importância do guia de viagem impresso como fonte explicativa da história e do espaço de uma cidade. Através de um corpus compreendendo quatro coleções de guias, esta pesquisa se atém aos modos de construção e à evolução da imagem turística de Lyon na primeira metade do século XX. Este estudo se inscreve numa pesquisa de doutorado em curso sobre a representação do espaço de Lyon entre a metade do século XIX e o final do século XX². O guia de viagem impresso constitui uma fonte importante para o pesquisador que estuda as representações urbanas e sua evolução. Na sua forma mais completa, esse gênero literário é composto de três materiais complementares: textos, ilustrações e mapas.

\section{O GUIA DE VIAGEM, UMA FONTE PARA O ESTUdO DA CIDADE}

Existe uma grande variedade de fontes textuais e iconográficas com referência espacial que podem dar informações sobre a imagem da cidade. Podemos citar, para o texto, o diário de viagem, a imprensa generalista ou especializada, os folhetos turísticos e, para a imagem, os cartazes, as vistas urbanas, os cartões-postais, os selos, as etiquetas comerciais. A maioria desses materiais dificilmente são utilizados no âmbito de um estudo científico em razão da quantidade de documentos a analisar e do relativo desconhecimento desses tipos de fontes.

Contrariamente à maioria desses documentos, o guia de viagem apresenta uma forte coerência, tornando-se uma fonte para estudar a imagem de um território e a representação dos espaços. As grandes coleções turísticas constituem uma fonte serial: as edições frequentes de obras publicadas por editores especializados tornam possível o estudo num período relativamente longo. Durante a primeira metade do século XX, o guia de viagem se caracteriza por forte estabilidade no nível da forma

2 PETERMANN, Damien. L'espace lyonnais représentéa à l'usage des voyageurs aux époques moderne et contemporaine, histoire et construction de l'image d'un territoire, XVII ${ }^{e}$ XX ${ }^{e}$ siècles. Tese (Doutorado) sob a orientação do professor Bernard Gauthiez, Université Jean Moulin Lyon 3 (co-diretor: Gilles Bertrand, Université Pierre Mendès France Grenoble 2), financiada pela Região Rhône-Alpes (ARC 7). 
e também em grande parte pelo conteúdo. Ao mesmo tempo produto turístico e obra literária, o guia responde a uma lógica editorial e econômica bastante específica. A análise aprofundada dos guias permite questionar sobre o papel, os objetivos e a estratégia dos diferentes atores na elaboração e evolução da imagem turística da cidade.

Até recentemente, e com raras exceções 3 , o guia de viagem não foi considerado como um objeto digno de grande interesse pela comunidade científica e pelas instituições culturais encarregadas da conservação dos documentos. Na Fança, as pesquisas sobre esse tipo específico de literatura foram multiplicadas ao longo dos últimos vinte anos, mas o reconhecimento dos guias como uma fonte útil e importante para o conhecimento do espaço ainda permanece bastante parcial.

Entre as pesquisas francófonas sobre os guias de viagem, é preciso citar o colóquio ocorrido em I998, cujos anais, publicados em 2000, constituem uma obra de referência sobre os guias de viagem4. Desde os anos 1990, diversas teses de doutorado foram destinadas a esse objeto de estudo. Pierre-Yves Saunier estudou 7I guias de Lyon do século XIX e do início do século XX ${ }^{5}$. A tese de Claire Hancock visava os guias de Paris e de Londres no século XIX ${ }^{6}$ e a de Marc Francon tinha por objeto a história do guia Vert Michelin7. Elsa Damien estudou em sua tese os guias de viagem da Itália no século XIX . Entre as pesquisas mais recentes, estão os trabalhos de Ariane Devanthéry sobre os guias relativos à Suíça nos séculos XVIII e XIX', assim como o número I5 da revista In Situ destinada aos guias de viagem ${ }^{\text {Io }}$.

A forma e o conteúdo do guia de viagem apresentam um cruzamento de diversas disciplinas. As pesquisas conduzidas nesses últimos anos sobre esse tipo de fonte

3 Para as pesquisas, citamos especialmente: CHABAUD, Gilles; MONZANI, Pierre. Les guides de Paris aux XVII et XVIII siècles, images de la ville. I979. Dissertação (Mestrado em História). Université Paris I, I979. Com relação à conservação, é preciso citar os fundos da Bibliothèque du Tourisme et des Voyages - Germaine Tillin (BTV), em Paris.

4 CHABAUD, Gilles; et al. (Dir.). Les guides imprimés du XVI ${ }^{e}$ au XXe siècle. Villes, paysages, voyages. Colloque I998. Université Paris VII. Paris: Belin, 2000.

5 SAUNIER, Pierre-Yves. Lyon au XIXe siècle: les espaces d'une cité. Tese (Doutorado em História). Université Lumière Lyon 2, I992.

6 HANCOCK, Claire. Paris et Londres au XIX ${ }^{e}$ siècle. Représentations dans les guides et récits de voyage. Paris: CNRS éditions, 2003.

7 FRANCON, Marc. Le Guide Vert Michelin. L'invention du tourisme culturel populaire. Paris: Economica, 2001.

8 DAMIEN, Elsa. La notion de guide à l'épreuve du tourisme naissant. Les voyageurs anglo-saxons en Italie à l'ère industriell. Tese (Doutorado em Estudos Italianos). Université Paris III, Sorbonne Nouvelle, 2004.

9 DEVANTHÉRY, Ariane. Itinéraires. Les guides de voyage en Suisse de la fin du XVIII siècle à I9I4. Pour une histoire culturelle du tourisme. Tese (Doutorado em Literatura). Université de Lausanne, 2008.

Io COHEN, Évelyne; VAJDA, Joanne; TOULIER, Bernard (Dir.). Le patrimoine des guides: lectures de l'espace urbain européen. In Situ: Revue des patrimoines, n. I5, 20II. Disponível em: 〈http://insitu.revues.org/III〉. Acesso em: out. 2016. 
refletem bastante a diversidade das abordagens disciplinares: literatura, história ${ }^{\mathrm{II}}$, história da $\operatorname{arte}^{\mathrm{I} 2}$, estudos italianos, semiologia, geografia, linguística ${ }^{\mathrm{I} 3}$, informática ${ }^{\mathrm{I} 4}$... A maioria desses trabalhos se concentra nos guias dos séculos XVIII-XIX e do início do século XX (até I9I4). Por outro lado, a literatura turística do século XX, e principalmente aquela entre as duas guerras, foi pouco estudada. E, no entanto, foi um período importante da história do turismo francês e europeu.

\section{O CONTEXTO TURístico Na FrançA NA PRimeira METAde do SÉculo XX}

Nos últimos anos do século XIX, dois organismos importantes ligados à viagem são fundados na França: o Touring Club de France - TCF (I890) e o Automobile-club de France (I895). O TCF, bastante ativo na promoção das cidades e regiões francesas, publica uma revista mensal ${ }^{15}$, assim como álbuns ricamente ilustrados ${ }^{\mathrm{I} 6}$. Em escala local, o primeiro sindicato de iniciativa ${ }^{17}$ é fundado em Grenoble em I889. O Sindicato de Iniciativa de Lyon e seu entorno (SIL) é fundado em $\mathrm{I}_{90 \mathrm{O}^{\mathrm{I}}}$.

II Ver especialmente os trabalhos de Gilles Bertrand sobre os guias e diários de viagem na Itália no século XVIII: Bibliographie des études sur le voyage en Italie. Voyage en Italie, voyage en Europe, XVIe-XXe siècle, Grenoble, Université Pierre Mendès France-CRHIPA, Les cahiers du CRHIPA n. 2, 2000, 30I p.; BERTRAND, Gilles. Le Grand Tour Le Grand Tour revisité. Pour une archéologie du tourisme: le voyage des Français en Italie, milieu XVIIIe siècle-début XIXe siècle. Rome: École Française de Rome. Collection de l’Ecole Française de Rome, $\mathrm{n}$. 398, 2008, 79I p.

I2 Ver o projeto em andamento “Guides de Paris (les historiens des arts et les corpus numériques)”, dirigido por Marianne Cojannot-Leblanc (Labex Les Passés dans le Présent), em parceria com a Bibliothèque Nationale de France. Disponível em: <http://www.passes-present.eu/fr/node/363〉. Acesso em: out. 2016.

I3 SEOANE, Annabelle. Les mécanismes énonciatifs dans les guides touristiques: entre genre et positionnements discursifs. Paris: L’Harmattan, 2013.

I4 Ver especialmente os trabalhos de Mauro Gaio (Laboratoire Informatique de l'Université de Pau et des Pays de l'Adour- Liuppa) sobre a extração automática de entidades espaciais nomeadas nos guias de viagem atuais. Disponível em: <http://dblp.uni-trier.de/pers/hd/g/Gaio:Mauro >. Acesso em: out. 2016.

I5 Touring Club de France, Revue Mensuelle. Disponível em Gallica: http://gallica.bnf.fr/ark:/I2I48/cb34350057f/ date.

I6 RECLUS, Onésime. À la France: sites et monuments. Paris: Touring Club de France, I900-I906. 32 v. Disponível em: 〈http://catalogue.bnf.fr/ark:/I2I48/cb3II856I4w>. Acesso em: out. 20I6. Touring Club de France. La France en images. 2 albums, I922. Disponível em Gallica: ${ }^{\text {ère }}{ }^{2}$ érie: 〈http://gallica.bnf.fr/ark:/I2I48/btvIbI050877Is.r〉 et $2^{\mathrm{e}}$ série: 〈http://gallica.bnf.fr/ark:/I2I48/btvIbI0508829p.r.>.

I7 De acordo com Marc Boyer, sindicato de iniciativa era um comitê "de pessoas conhecidas que voluntariamente davam informações e prestavam serviços aos habitantes" e tinha "como objetivo atrair e acolher bem os turistas”. BOYER, Marc. História do turismo de massa. Bauru: Edusc, I999 apud SANTANA, Nara Maria Carlos de (Org.). Turismo entre diálogos. Interpretações sobre gestão, política, cultura e sociedade. Rio de Janeiro: Faperj/e-papers, 20I2, p. I9. (N. T.).

I8 CREATION d'un Syndicat d'initiative dans l'intérêt de la Ville de Lyon et ses environs, I9or, 4 p., Lyon, Musées Gadagne, inv. I895.8. 
Nessa época, o trem é o meio de transporte preferido dos viajantes, enquanto o uso da bicicleta e do automóvel começa a se desenvolver. Em nível nacional, estruturas aparecem a fim de tratar questões relativas ao turismo. O Serviço Nacional do Turismo é criado em I9Io. A lei sobre a criação das estações hidrominerais, climáticas e turísticas, votada em I9I9, institui a aplicação da taxa de estadia em cada uma das cidades em questão. Após um pedido do conselho municipal, Lyon é oficialmente classificada como estação turística em I92I, e uma câmara da indústria turística é criada na cidade ${ }^{\text {I9. }}$. Em I936, a lei instituindo duas semanas de férias pagas ${ }^{20}$ e o estabelecimento do billet populaire de congé annuel (bilhete popular de férias anual bilhete de trem com tarifa reduzida) dão origem a um turismo de massa na França. No mesmo ano é criada a Subsecretaria de Estado de Lazer, dirigida por Léo Lagrange.

\section{O turismo e a guerra}

As duas guerras mundiais (I9I4-I9I8 e I939-I945) tiveram consequências importantes na mobilidade dos viajantes e no desenvolvimento do turismo na França.

Em I9I4, a entrada da França na guerra contra Alemanha e Áustria-Hungria afeta fortemente a Exposição Internacional Urbana de Lyon e, consequentemente, uma grande parte da atividade turística da cidade ${ }^{2 \mathrm{I}}$. Muitos viajantes presentes em Lyon no início do século XX eram alemães e austríacos. O Sindicato de Iniciativa de Lyon possuía, além disso, excelentes relações com a imprensa desses dois países, em particular o Illustrirte Zeitung, jornal editado em Leipzig ${ }^{22}$. Após a guerra, supõe-se que o SIL não tenha mais nenhuma relação com as nações vencidas e passe a tentar atrair para Lyon os viajantes britânicos e da América do Norte.

A quantidade de publicações relacionadas ao turismo é fortemente reduzida nos anos pós-guerra. Em I9I8, numerosos empregados das editoras foram mortos durante a guerra, e os custos das impressões aumentaram significativamente com o aumento do preço do papel ${ }^{23}$. A atualização das edições de guias é bastante complicada nos períodos pós-guerra em razão da destruição urbana e da desorganização geral do país. No prefácio do guia Hachette Bourgogne, Franche-Comté, Morvan, Jura, Lyonnais, de I920, o diretor da coleção dos Guides Bleus, Marcel Monmarché, advertia assim o leitor:

I9 Journal officiel de la République française. Lois et décrets, I3 mars I92I, année 53, n. 7I, p. 3I59-3I60. Disponível em Gallica: 〈http://gallica.bnf.fr/ark:/22I48/bpt6k64394I7f.r>. Acesso em: out. 2016 .

20 A lei de 20 de junho de I936 institui férias anuais pagas na indústria, no comércio, nas profissões liberais, nos serviços domésticos e na agricultura.

2I PRIVAT-SAVIGNY, Maria-Anne (Dir.). Lyon, centre du monde! L'exposition internationale urbaine de 1914. Catálogo da exposição. Lyon: musées Gadagne, 2013.

22 Syndicat d'Initiative de Lyon. Lyon-Touriste. $1^{\mathrm{er}}$ août 1907, $2^{\mathrm{e}}$ année, n. 8, p. 2.

23 HUBÉ, Nicolas; CHUPIN, Ivan; KACIAF, Nicolas. Histoire politique et économique des médias en France. Paris: La Découverte, 2009, p. 46. 
[...] notre travail accompli pendant la guerre et dans la période de l'armistice s'est heurté à bien des difficultés [...]: beaucoup d'hôtels, de casinos, d'établissements publics transformés en hôpitaux n'ont pas encore rouvert; partout les prix d'hôtel ont subi et subiront encore des fluctuations [...], les services des chemins de fer, des voitures publiques, etc., ont été complètement bouleversés; certains musées, châteaux, etc., ont été provisoirement fermés aux visiteurs²4.

Vinte e sete anos mais tarde, seu filho, Georges Monmarché, que o sucedeu na direção da coleção, apresenta basicamente o mesmo discurso no guia France automobile en un volume:

Certains musées ont été détruits pendant la guerre 1939-45. Nous les avons signalés. D’autres ont été ou sont encore fermés pour un temps indéterminé. Le lecteur voudra bien se renseigner sur place. [...] En raison de l'instabilité actuelle, les chiffres de population sont donnés d'après le dénombrement de I936. [...] La situation mouvante de l'hôtellerie ne nous a pas permis d'établir des listes auxquelles le voyageur puisse se fier aussi parfaitement qu'autrefois. Beaucoup d'hôtels ont été détruits; nous les avons supprimés dans notre guide. D'autres sont réquisitionnés, mais seront rendus à la clientèle dans un avenir plus ou moins proche. D'autres sont encore en voie de réinstallation. Nous avons cru bon de les laisser figurer au nombre des hôtels ouverts, mais le voyageur devra se renseigner sur place. [...] Nous nous excusons auprès de nos lecteurs des inévitables lacunes que comporte la rédaction d'un Guide dans cette période d'après-guerre. Certains détails n'ont pu encore être recueillis dans les régions sinistrées, et pour les villes de moindre importance, qui n'ont pas subi de dégâts dans leur patrimoine artistique, nous nous sommes bornés quelquefois à la description d'avant-guerre ${ }^{25}$.

Após o conflito, muitos anos foram necessários para os ajustes das edições atualizadas.

24 “[...] nosso trabalho durante a guerra e no período de armistício encontrou muitas dificuldades [...]: muitos hotéis, cassinos, estabelecimentos públicos transformados em hospitais ainda não reabriram; em todos os lugares os preços dos hotéis sofreram e sofrerão ainda flutuações [...], os serviços das estradas de ferro, dos transportes públicos etc. foram completamente atingidos; alguns museus, castelos etc. foram temporariamente fechados aos visitantes." MONMARCHÉ, Marcel (Dir.). Bourgogne, Franche-Comté, Morvan, Jura, Lyonnais. Paris: Hachette, I920, p. VI.

25 "Alguns museus foram destruídos durante a guerra I939-45. Nós os havíamos advertido. Outros foram ou estão ainda fechados por tempo indeterminado. O leitor gostaria muito de se informar sobre o local. [...] Em função da instabilidade atual, os números de população são dados após a contagem de I936. [...] A situação instável do setor hoteleiro não nos permitiu estabelecer listas nas quais o viajante possa se orgulhar tão perfeitamente como antes. Muitos hotéis foram destruídos; nós os suprimimos do nosso guia. Outros estão tomados pelos militares, mas serão oferecidos aos clientes num futuro mais ou menos próximo. Outros estão ainda em vias de reinstalação. Nós acreditamos que seria bom deixá-los figurar no número de hotéis abertos, mas o viajante deverá se informar no local. [...] Pedimos desculpas aos nossos leitores acerca das inevitáveis lacunas existentes na redação de um guia neste período de pós-guerra. Alguns detalhes não puderam ainda ser recolhidos nas regiões afetadas e, para as cidades de menor importância, que não sofreram danos no seu patrimônio artístico, nós nos limitamos, em alguns casos, à descrição do pré-guerra.” MONMARCHÉ, Georges (Dir.). France automobile en un volume. Paris: Hachette, I947, p. VIII-X. 
Se a guerra é um obstáculo à viagem de lazer, ela torna possível, no entanto, o aparecimento de muitas formas inusitadas de turismo. Assim, durante a Primeira Guerra Mundial, os turistas tradicionais são bem menos numerosos em Lyon que antes da guerra. A revista do SIL, Lyon-touriste, diagnostica, em I9I5, a presença de novos turistas: são os soldados atingidos na guerra, atendidos nos hospitais de Lyon, que conhecem a cidade em companhia de suas famílias que vieram visitá-los. Durante a Segunda Guerra Mundial, alguns documentos turísticos são publicados especificamente para as forças armadas. É o caso do Deutscher Wegleiter für Paris, um periódico de uma centena de números impressos em Paris entre I940 e I944 ${ }^{26}$. Essa publicação esclarece os soldados alemães sobre os locais de lazer da capital e contém críticas de peças de teatro, filmes e exposições. Em I944, um guia destinado às cidades do sul da França é publicado pelo departamento de guerra americano para o uso dos soldados que foram combater naquele país ${ }^{27}$. O prefácio dessa obra recomenda aos militares que aproveitem a oportunidade que se apresenta a eles de visitar o país, advertindo-os sobre as destruições e mudanças que poderiam ocorrer durante o conflito:

About the only thing in this booklet that can be guaranted is the terrain. The rest of it is up to the fortunes or misfortunes of war. [...] The short historical notes and city plans concerning most of the towns are correct as of the outbreak of the war. But the changes of war were still happening in many places when this pocket guide went to press. [...] Anyhow, so far as your military duties permit, see as much as you can. You've got a great chance to do now, major expenses paid, what would cost you a lot of your money after the war. Take advantage of it ${ }^{28}$.

É preciso também mencionar o aparecimento do turismo de memória ligado às

26 A esse respeito, ver: GORDON, Bertram M. Ist Gott Französisch? Germans, tourism, and occupied France, I940-I944. Modern e contemporary France, 4:3, I996, p. 287-298; GEIGER, Wolfgang. Chapitre X. Regards croisés sur la France I940-I944. In: ___ _. L’image de la France dans l'Allemagne nazie: I933-I945. Rennes: Presses Universitaires de Rennes, I999, § 242. Disponível em: 〈http://books.openedition.org/pur/9296〉. Acesso em: out. 2016.

27 UNITED STATES. Army Service Forces. Information and Education Division. Pocket guide to the cities of Southern France. Washington D. C., I944, VI-82 p. Disponível em: <https://archive.org/details/ PocketGuideToTheCitiesOfSouthernFrance . Acesso em: out. 2016.

28 "A única coisa neste livro que pode ser garantida é o terreno. O resto depende das fortunas ou desgraças da guerra. [...] As breves notas históricas e as plantas referentes à maioria das cidades estão corretas desde o início da guerra. Mas as transformações oriundas da guerra ainda estavam acontecendo em muitos lugares quando este guia de bolso foi para a impressão. [...] De qualquer modo, até onde as suas forças militares o permitam, veja o máximo que puder. Você tem uma grande chance de fazer agora, com as despesas pagas, o que custaria muito do seu dinheiro depois da guerra. Aproveite." Ibidem, p. III-IV. 
batalhas que se desenvolveram durante a Primeira Guerra Mundial. Assim, a editora Michelin publica guias dos campos de batalha desde I9I $7^{29}$.

\section{O SindiCATO DE INICIATIVA DE LYON E SEU ENTORNO}

O SIL é um organismo privado e independente, fundado em I90I, que possui estreitas ligações com as esferas política, econômica e comercial de Lyon. Nesse sentido, a lista de membros do SIL em I906 contém nomes de comerciantes, proprietários de hotéis, banqueiros, industriais, advogados e médicos. Muitas personalidades políticas locais também fazem parte dessa lista: os conselheiros municipais Gorjus e Nové-Josserand, assim como o professor Beauvisage, adjunto ao prefeito de Lyon e eleito senador do Rhône em I909. Há também diversos representantes oficiais de países estrangeiros: 0 cônsul do México, o cônsul da Bélgica, o cônsul suíço, o vice-cônsul do Brasil (Édouard Payen) e o vice-cônsul do Chile. Diversos membros do SIL são eleitos pela Câmara do Comércio, outros são membros eruditos de sociedades científicas.

Desde a sua criação, o SIL é bastante ativo na promoção turística de Lyon no exterior. Os objetivos são claramente anunciados em cada uma das publicações, principalmente na revista Lyon-Touriste:

\section{Le Syndicat d'initiative a pour but:}

$I^{\circ}$ D’attirer à Lyon les étrangers par une publicité incessante en brochures, journaux et affiches.

$2^{\circ}$ De les y retenir en leur donnant tous les renseignements nécessaires pour la visite de la ville et de ses environs, et en favorisant de tout son pouvoir, en les provoquant au besoin, les fêtes, concours et expositions.

$3^{\circ}$ De donner à nos compatriotes toutes les indications utiles pour les voyages et excursions qu'ils veulent entreprendre, aussi bien que pour les aider dans le choix d'un lieu de villégiature estivale ou hivernale ${ }^{30}$.

O SIL está relacionado a muitos jornais estrangeiros, nos quais publicou anúncios contendo "uma vista de Lyon com esta citação: ‘Turistas, venham a Lyon, uma das

29 A esse respeito, ver: BRANDT, Susanne. Le voyage aux champs de bataille. Vingtième Siècle, revue d'histoire, n. 4I, janvier-mars I994, p. I8-22. Disponível em: 〈www.persee.fr/doc/xxs_0294-I759_I994_num_4I_I_3262〉. Acesso em: out. 20I6; HARP, Stephen L. Touring the Trenches. Michelin Guides to World War I Battlefields. In: . Marketing Michelin: advertising \& cultural identity in twentieth-century France. Londres: J. Hopkins University Press, 200I, p. 89-I25.

30 "O Sindicato de iniciativa tem por objetivo: $I^{\circ}$ Atrair a Lyon os estrangeiros através de uma publicidade incessante em folhetos, jornais e cartazes. $2^{\circ}$ Fornecer-lhes todas as informações necessárias para a visita à cidade e a seu entorno e, aproveitando-se de todo o seu poder, proporcionar-lhes, de acordo com a necessidade, acesso a festas, concursos e exposições. $3^{\circ}$ Dar a nossos compatriotas todas as indicações úteis para as viagens e excursões que eles querem realizar, assim como para ajudá-los na escolha de um local de férias no verão ou no inverno." Syndicat d'initiative de Lyon. Lyon-Touriste. $\mathrm{I}^{\mathrm{er}}$ septembre I906, I $\mathrm{I}^{\mathrm{re}}$ année, n. 9, p. I. 
mais belas cidades da Europa'”3I. Entre I906 e I9I0, esse anúncio está também presente no Graphic, jornal inglês, e nos três jornais alemães: Illustrirte Zeitung, Weltcourrier e Modern Kunst. Os relatórios do Lyon-Touriste mencionam também contatos com o Daily Telegraph para negociar um encarte publicitário. Uma versão um pouco diferente dessa visão turística foi publicada na agenda PLM de I92I (figura I). O SIL procura também atrair turistas americanos que vão para a Europa, por intermédio de anúncios inseridos no Journal de l'Atlantique, revista distribuída nos navios transatlânticos.

\section{TOLRISTES VENEZ X LYON!} JOLIES VILLES DE LEUUROPE
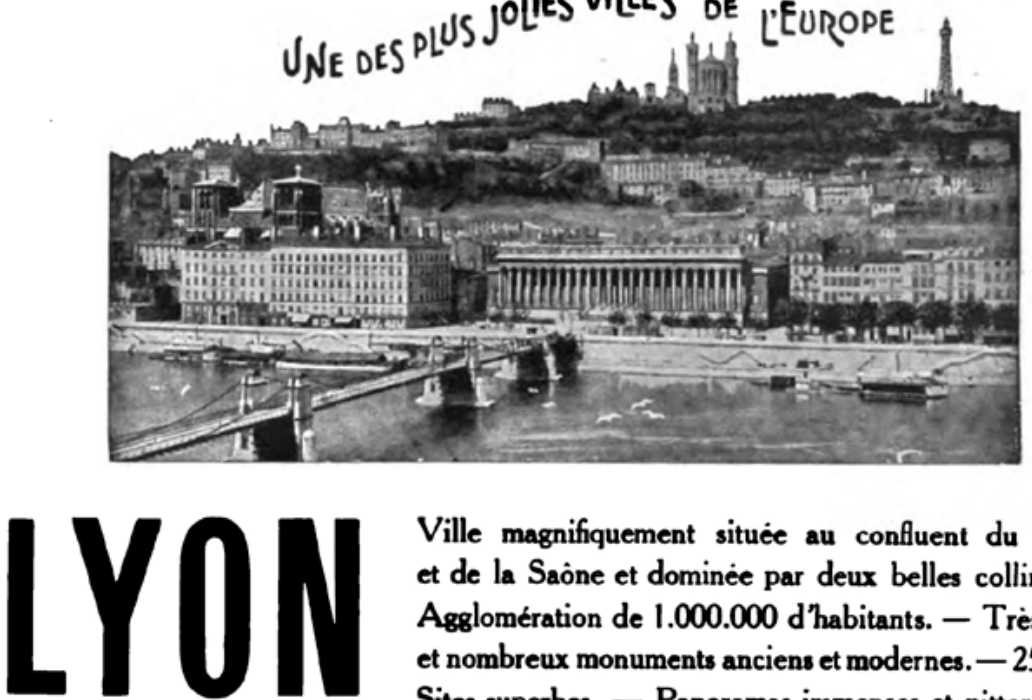

Ville magnifiquement située au confluent du Rhòne et de la Saone et dominee par deux belles collines. Agglomération de 1.000 .000 d'habitants. - Très beaux et nombreux monuments anciens et modernes. -25 ponts. Sites superbes. - Panoramas immenses et pittoresques. Vastes places, belles avenues, quais splendides uniques au monde. - Cuisine particulièrement réputée. - Siège d'une Université, d'une Cour d'Appel, d'un Corps d'Armée. d'un Archevèchè, d'une Préfecture. - Point de dèpart del'inoubliable Descente du Rhône.

Sur demande, le SYNDICAT d'INITIATIVE, Place Bellecour

envoie contre 50 centimes en timbres une très belle brochure illustrée de nombreuses photographles.

Figura I - Anúncio do SIL. Fonte: Agenda PLM - Paris-Lyon-Méditerranée. Vers la renaissanse du tourisme. Paris: Compagnie PLM, de I92I, p. 225

A revista do SIL, Lyon-Touriste, é publicada de I906 até I944. Inicialmente de tiragem mensal, ela se torna trimestral. Essa publicação contém os "relatórios [das] sessões, indicações dos procedimentos realizados junto à municipalidade de Lyon ou das companhias de transporte para o embelezamento da nossa cidade, a

3I Syndicat d'initiative de Lyon. Lyon-Touriste. $\mathrm{I}^{\mathrm{er}}$ mars I908, $3^{\mathrm{e}}$ année, n. 3, p. 4. 
salvaguarda de nossos passeios e monumentos ou para obter facilidade de acesso e de comunicação"32.

Ela reproduz, às vezes, artigos publicados na imprensa de Lyon (Le salut public, Lyon-Républicain) no que diz respeito ao turismo ou à promoção de Lyon no exterior, ao embelezamento da cidade e aos problemas que podem prejudicar o turismo. A tiragem da revista é de I.500 exemplares em I906, e 2.000 em I907 ${ }^{33}$. É distribuída nos hotéis da região, nas bibliotecas municipais, e enviada a outros sindicatos de iniciativa locais.

O SIL é apoiado financeiramente pela Câmara de Comércio ${ }^{34}$, pelo Conselho Geral do Rhône, pelo Touring-Club de France, pelos bancos, pelos diversos sindicatos patronais, pelos industriais, pelos negociadores ${ }^{35}$ e pelo município de Lyon a partir de $1906^{36}$.

\section{CoRPus DE ESTUdo}

O corpus de estudo reúne 44 edições de guias de Lyon, pertencendo a quatro coleções turísticas distintas ${ }^{37}$. São obras publicadas entre I900 e I950, por dois editores locais (o SIL e a sociedade de guias POL), uma importante editora francesa (Hachette) e uma célebre editora alemã (Baedeker). Esse corpus assim constituído apresenta o interesse de confrontar a representação de Lyon nos guias de quatro coleções com graus diferentes de importânica, durante a primeira metade do século XX.

\section{Os guias Hachette}

Hachette é, no século XX, a coleção francesa de referênca em matéria de obras ligadas ao turismo. Desde I857, Hachette edita a coleção dos Guides Joanne, que se tornam em I9I9 os Guides Bleus ${ }^{38}$. Numerosos títulos são publicados, contendo diferentes lugares na França e no exterior. Existem monografias locais (Lyon et ses environs), guias contendo uma vasta região (Bourgogne, Morvan, Jura, Lyonnais, Sud-Est) ou então guias de todo o país (France automobile en un volume). Nos anos I920-I930, os viajantes utilizam cada vez mais o automóvel em relação ao trem, e a evolução dos títulos dos guias Hachette traduz essa importante mudança. Em I923, o título France en 4 volumes foi dividido de acordo com as grandes redes de estradas de ferro (a parte "Lyon" se encontrava então no volume Sud-Est, Le réseau PLM. Em I938, o guia

32 Syndicat d’initiative de Lyon. Lyon-Touriste. $\mathrm{I}^{\mathrm{er}}$ mars I907, $2^{\mathrm{e}}$ année, n. 3, p. 2.

33 Ibidem.

34 Desde I902, a Câmara de Comércio deposita ao SIL um subsídio de I.ooo francos.

35 Syndicat d’initiative de Lyon. Lyon-Touriste. $\mathrm{I}^{\mathrm{er}}$ mars I906, $\mathrm{I}^{\mathrm{re}}$ année, n. 3, p. 5.

36 O subsídio depositado ao SIL pela cidade de Lyon foi de I.000 francos em I906 e de I.500 francos em I907.

Syndicat d'initiative de Lyon. Lyon-Touriste. $\mathrm{I}^{\mathrm{er}}$ mars $1907,2^{\mathrm{e}}$ année, n. 3, p. 3.

37 Esse corpus reúne I8 guias Hachette, 9 guias Baedeker, I2 folhetos-guia do SIL e 5 guias POL (Apêndice I).

38 MORLIER, Hélène. Les Guides-Joanne, Genèse des Guides-Bleus. Paris: Les Sentiers débattus, 2007, p. 16. 
Hachette destinado à descrição do país se intitula, a partir de então, France automobile en un volume.

\section{Os guias Baedeker}

Desde I832, a editora alemã Baedeker, situada em Leipzig, publica os guias de viagem, que são muito renomados na Europa ${ }^{39}$. A grande particularidade de Baedeker é que foram publicadas obras em três línguas diferentes (alemão, inglês e francês), o que lhe permite ser um sério concorrente de Hachette na França. A parte destinada a Lyon se encontra nos guias da parte do sudeste da França. A Primeira Guerra Mundial marca uma ruptura importante para Baedeker, que não edita mais nenhum guia em língua francesa, à exceção daqueles sobre a Bélgica e Luxemburgo.

\section{Os folhetos-guia SIL}

A partir de I902, o SIL edita um folheto-guia anual sobre Lyon, distribuído gratuitamente. No início foi chamado de Lyon-pittoresque e evolui sensivelmente a partir de I929, tornando-se Lyon - guide officiel illustré. O folheto-guia do SIL contém numerosas ilustrações (fotografias em preto e branco) e muita publicidade $4^{\circ}$.

Na edição de I9I3, a descrição da cidade no folheto-guia começa pela seguinte frase:

Au point de vue pittoresque, Lyon offre tous les signes distinctifs d'une Capitale, non moins que sous le rapport de sa situation géographique, de sa richesse industrielle et commerciale, de son essor économique, de la célébrité de son Université, de son influence artistique et scientifique, de son rayonnement intellectuel et de l'intensité de sa vie administrative ${ }^{4}$.

\section{Os guias POL}

A Sociedade dos Guias POL, dirigida por Gustave Toursier, foi fundada em I896. As informações disponíveis sobre essa coleção são pouco numerosas. Ela edita, desde o fim do século XIX, guias em língua francesa sobre diferentes cidades e regiões, na França e em alguns países vizinhos. Existem títulos destinados a Paris, Lyon, Grenoble, Avignon, Marseille, Dijon, Vichy, Genebra, Chamonix, Le-Puy-en-Velay, Gênes, assim como aos Alpes, à côte d'Azur e ao vale do Rhône. As edições do Guide pratique de Lyon et de sa région são frequentes durante a primeira metade do século

39 Ver a bibliografia dos guias Baedeker: HINRICHSEN, Alex W. Baedeker's Reisehandbücher, 1832-1990: Bibliographie 1832-1944: Verzeichnis 1948-1990: Verlagsgeschichte mit Abbildungen und zusätzlichen Übersichten. 2. ed. Bevern:

U. Hinrichsen, 1991.

40 Syndicat d'initiative de Lyon. Lyon-Touriste. $1^{\text {er }}$ mars 1906, $1^{\text {re }}$ année, n. 3, p. 3.

4I "Do ponto de vista pitoresco, Lyon oferece todos os sinais distintos de uma capital, não menos que sobre a relação de sua situação geográfica, de sua riqueza industrial e comercial, de seu desenvolvimento econômico, de sua célebre universidade, de sua influência artística e científica, de sua influência intelectual e da intensidade de sua vida administrativa." Syndicat d'initiative de Lyon. Lyon-Pittoresque. Lyon, I9I3, p. I3. 
XX. Os escritórios da Sociedade dos Guias POL situavam-se na Praça Bellecour, número I9, próximo ao escritório do SIL.

Os guias Hachette e Baedeker são bastante utilizados pelos viajantes presentes em Lyon se levarmos em conta a revista Lyon-Touriste, que chama, em I903, os estrangeiros que visitam a cidade como "seus Joanne ou seus Baedeker à mão"42. As edições dos guias Baedeker cobrem uma vasta região e são desprovidas de ilustrações e publicidade. Os guias do SIL e os guias POL contêm numerosas imagens de Lyon e diversas plantas da cidade. Quanto aos guias Hachette, isso depende dos títulos. Aqueles destinados a toda a França ou a uma região extensa não são ilustrados, diferentemente dos guias destinados a Lyon e seu entorno (figura 2).

PLACE BELLECOUR.

\title{
Quartier Bellecour.
}

\begin{abstract}
Moyens de communication. - Presque tout le réseau des trams passe ou aboutit a la pl. Bellecour ( $V$. ci-dessous).

As pect général. - C'est le quartier des élégances de Lyon. Au S. et sur la pl. même se concentre la vie de l'aristocratie et de la haute bourgeoisio. Au N. commence le mouvement commercial.
\end{abstract}

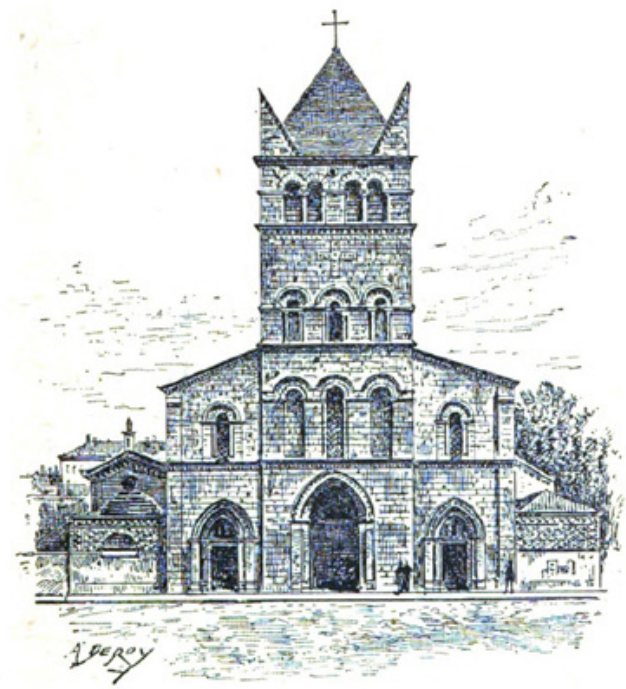

Saint-Martin d'Ainay.

Continuant à remonter la rue Victor-Hugo on voit à l'angle de la rue Sala (entrẻe par la rue Boissac) l'ancien hótel Varissan, auj. Hólel du Gouverneur, commandant le $14^{\circ}$ Corps d'armée et généralissime de l'armée des Alpes.

La superbe place Bellecour (PI. E, 3 ; $310 \mathrm{~m}$. de long. sur $200 \mathrm{~m}$. de larg.), encadrée par deux belles façades construites en 1800 pour remplacer celles détruites en 1793 , qui avaient été exécutées sur les dessins de Mansart, est ornée de jardins, de fontaines (puissants jets d'eau) et décorée au centre de la statue équestre de Louis XIV, par Lemot. Elle est par excellence la promenade lyonnaise à la mode et le rendez-vous des étrangers, surtout aux heures des concerts

Figura 2 - Fonte: PAILLON, Maurice, I905, p. 23

42 Syndicat d'initiative de Lyon. Lyon-Touriste. $\mathrm{I}^{\mathrm{er}}$ mars I906, I ${ }^{\mathrm{re}}$ année, n. 3, p. 3. 
Existem alguns elos entre os diferentes editores de guias. Por exemplo, um número de Lyon-Touriste de I909 menciona uma carta enviada ao SIL por Marcel Monmarché, diretor da coleção dos guias Joanne, "solicitando sua inscrição como membro do sindicato" 3 . Maurice Paillon, autor do guia Hachette Lyon et ses environs de I905, é membro do SIL, onde exerce a função de administrador. Enfim, o diretor dos guias POL, Gustave Toursier, é também citado entre os membros do SIL. Essas relações entre autores e editores de guias franceses sobre Lyon (SIL, Hachette, POL) foram importantes nos anos I900-I920.

\section{Outras publicações turísticas}

Além dessas coleções, existem inúmeras outras publicações turísticas (guias, revistas, folhetos) incluindo uma parte destinada à visita a Lyon. Algumas obras são dedicadas a um itinerário regional no qual Lyon é apenas uma simples passagem. É o caso das agendas publicadas pela Compagnie des Chemins de fer de Paris à Lyon et à la Méditerranée (PLM) e dos guias sobre os Alpes ou a Côte d'Azur. Esses documentos, que podem trazer esclarecimentos interessantes, não foram integrados ao corpus do estudo em razão da sua grande heterogeneidade e porque não apresentam a mesma coerência no seu conjunto como as coleções turísticas escolhidas.

\section{O guia DE VIAGEM, DOCUMENTO DE DIFícil ACESSO PARA O PESQUISADOR}

O pesquisador que escolhe estudar os guias de viagem se encontra rapidamente frente a um problema de acessibilidade aos dados. Poucos exemplares são conservados nas coleções públicas, seja em bibliotecas, arquivos ou museus. As pesquisas nos arquivos privados de editoras especializadas em turismo se apresentam mais bem-sucedidas, sem, contudo, serem suficientes. Assim, os arquivos da editora Hachette ${ }^{44}$ contêm inúmeras edições dos Guides Joanne e Guides Bleus, mas estamos bem distantes da exaustividade. Determinadas edições de guias, publicados no início do século XX, foram digitalizadas. Essas obras, que desde então são de domínio público, podem ser consultadas em sites especializados, como Google Books, Gallica, Internet Archive. No entanto, a qualidade da digitalização é bastante desigual e pode apresentar diversos problemas, principalmente no Google Books. Em geral, a totalidade do texto está disponível, a menos que haja erros de digitalização (páginas em falta ou dobradas). Por outro lado, as ilustrações são pouco exploradas (baixa resolução, imagem muito escura), e as plantas, dobradas, com frequência não foram digitalizadas na sua totalidade. Finalmente, a melhor solução permanece na consulta do exemplar

43 Syndicat d'initiative de Lyon. Lyon-Touriste. $\mathrm{I}^{\mathrm{er}}$ janvier I909, $4^{\mathrm{e}}$ année, n. I, p. 3.

44 Os exemplares da editora Hachette foram arquivados em 1993 no Institut de la Mémoire Ecrite Contemporaine - Imec (Abbaye d'Ardenne, I4280 Saint-Germain-la-Blanche-Herbe, França). Para outras informações, consultar a descrição dos arquivos Hachette em: IMEC - Institut Mémoires d'Édition Contemporaine. Les collections. Hachette Livre. Disponível em: <www.imec-archives.com/fonds/ hachette-livre>. Acesso em: out. 2016. 
impresso. Muitas vezes é possível consultar os guias pertencentes a colecionadores particulares, que em geral se mostram de acordo em fornecer uma autorização para pesquisas científicas. Enfim, o pesquisador tem também o interesse de constituir sua própria coleção pessoal através da compra de guias usados, que são regularmente vendidos em livrarias de usados e na internet.

\section{AS DUAS DIMENSÕES DE LEITURA DOS GUIAS DE VIAGEM}

Para a análise do guia de viagem impresso é necessário distinguir duas dimensões de leitura. O guia pode ser estudado a partir de numerosas informações suscetíveis aos interesses dos pesquisadores de diferentes disciplinas: história, história da arte, urbanismo, geografia, transportes, arquitetura... Esse tipo de documento contém principalmente informações sobre os serviços e equipamentos urbanos: cafés, restaurantes, hotéis, correios, consulados, bancos, teatros, cinemas, bibliotecas... Por exemplo, o Guide pratique de Lyon ${ }^{45}$, publicado pela editora POL por volta de I922, contém informações precisas de cada linha de bonde: número da linha, estações de chegada e saída, estações intermediárias e principais e duração total do trajeto46. Esse mesmo guia contém também uma planta de Lyon, bastante interessante, mostrando a mancha urbana (figura 3).

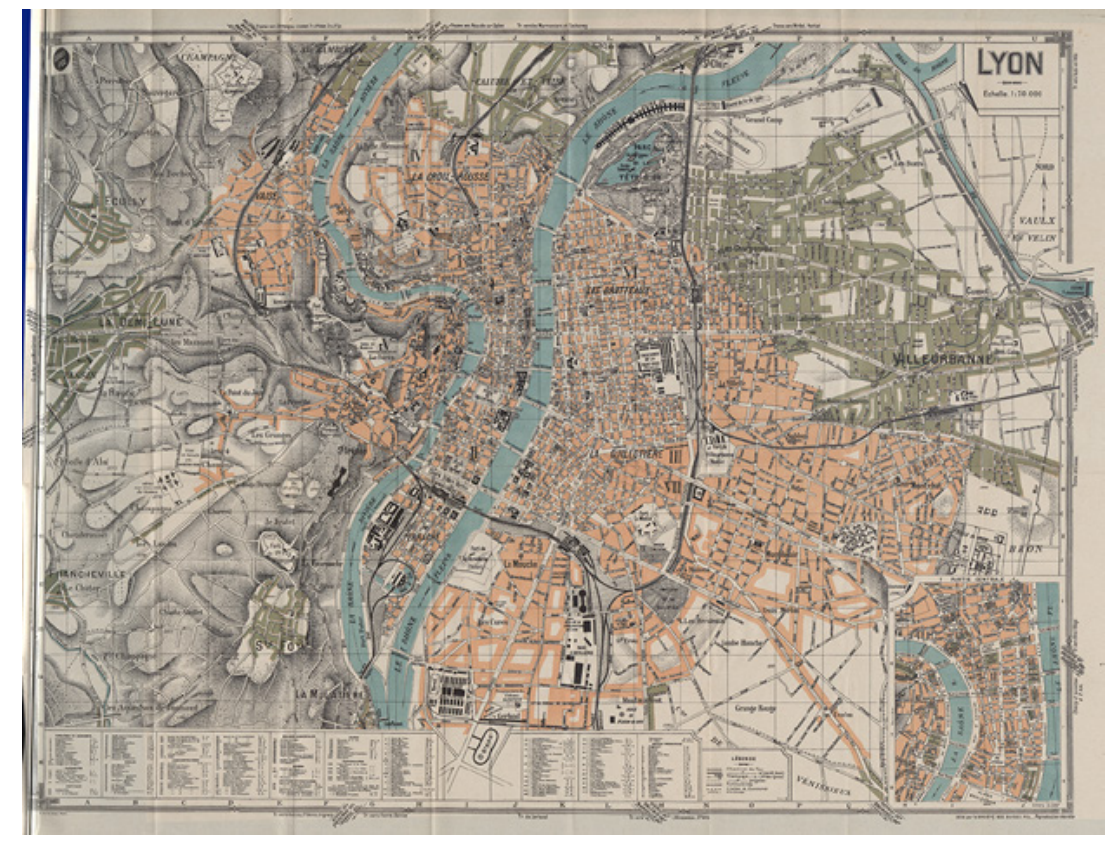

Figura 3 - Planta de Lyon e seu entorno. Fonte: TOURSIER, Gustav, [I922?]

45 TOURSIER, Gustave (Dir.). Guide pratique de Lyon et de sa région. II. ed. Lyon: Société des Guides POL, [I922?]. 46 Ibidem, p. Io-II. 
O guia de viagem tem por objetivo informar o leitor sobre o que há de interessante num território. As recomendações presentes no guia têm importante valor prescritivo para o viajante. Por essência, o guia não diz tudo: há uma seleção da mensagem. O pesquisador pode assim se interessar pela maneira pela qual o guia valoriza determinadas informações em relação a outras. A análise do discurso, a investigação dos elementos ausentes no guia e aqueles especialmente mais valorizados são bastante interessantes. Este estudo necessita levar em consideração o contexto de produção, o conteúdo e a forma do guia e buscar estruturar os objetivos dos autores. As diferentes coleções turísticas recorrem a diversos meios tipográficos a fim de estabelecer uma hierarquia entre os elementos mencionados. A mensagem é fortemente estruturada, os pontos de interesse são hierarquizados com o auxílio de símbolos (estrelas, asteriscos). No corpus, esse tipo de símbolo aparece pela primeira vez nos guias Baedeker. A tipografia (negrito, itálico, letras maiúsculas) é igualmente utilizada nos guias de viagem para diferenciar as entidades espaciais nomeadas seguindo alguns níveis de interesse. O estudo do vocabulário associado aos diferentes espaços e objetos urbanos traz também elementos particularmente esclarecedores.

\section{ESTRUTURA DO GUIA DE VIAGEM}

A maioria dos guias de Lyon reunidos no corpus adotam uma organização similar do conteúdo. Frequentemente, a visita à cidade é separada em três grandes partes, em função dos rios: Presqu'île (e Croix-Rousse)/margem direita do Saône (Vieux Lyon e Fourvière)/margem esquerda do Rhône (Brotteaux et Guillotière). Essa divisão espacial, que estava presente em determinados guias de Lyon na metade do século XIX ${ }^{47}$, aparece progressivamente nas quatro coleções estudadas.

Assim, os guias Baedeker adotam essa organização desde a edição alemã de $1898^{48}$ e, depois, na edição francesa de $1906^{49}$ e na edição inglesa de $1914^{\circ}$. A edição alemã de I930 retoma a mesma estrutura.

Na coleção dos Guides Joanne (Hachette) a edição I905 do guia Lyon et ses environs ${ }^{5 I}$ é a primeira a dividir a cidade em função do espaço e não mais em função das categorias temáticas utilizadas anteriormente (edificações religiosas e civis, praças, ruas). No entanto, é somente a partir de I920 que uma tripla organização (cidade central - cidade antiga - cidade nova) se torna a regra nos guias Hachette de Lyon. Verificou-se que, na edição de I944 do Guide Bleu Lyon et ses environs, além da divisão

47 SAUNIER, Pierre-Yves, op. cit, p. 50.

48 BAEDEKER, Karl. Die Riviera, das südöstliche Frankreich, Korsika, die Kurorte an den oberitalienischen Seen und am Genfer See. I. ed. Leipzig: Karl Baedeker, I898.

49 Idem, Le Sud-Est de la France du Jura à la Méditerranée y compris la Corse. 8. ed. Leipzig: Karl Baedeker e Paris: Paul Ollendorff, I906.

50 Idem, Southern France including Corsica. 6. ed. Leipzig: Karl Baedeker e Londres: T. Fischer Unwin, I9I4.

5 I PAILLON, Maurice. Lyon et ses environs. Paris: Hachette, I905. 
clássica, uma quarta seção é presente, destinada ao “urbanismo moderno de Lyon” 52 . Nessa parte são apresentados os projetos urbanos recentes e aqueles realizados: Villeurbanne, bairro dos Hospitais, aeroporto de Bron, bairro de Gerland (Estádio Municipal e edifício dos Abatedouros).

Desde a primeira edição (I902), os folhetos-guia do SIL propõem uma visita à cidade organizada de acordo com um recorte geográfico. A edição de I902 contém, assim, seis espaços - Lyon-Bellecour (da estação de Perrache até a igreja Saint-Nizier), Lyon-Fourvière (Fourvière, Saint-Jean e Vieux-Lyon), Lyon-Vaise, Lyon-Terreaux $e$ Croix-Rousse (a Câmara Municipal e o Palais des Arts), Lyon-Brotteaux (Parc de la Tête-d'Or), Lyon-Guillotière (a Universidade e a Prefeitura) -, aos quais se adiciona uma seção dedicada aos cais de Lyon. A edição seguinte, em I903, adota praticamente a mesma estrutura. A única diferença é a adição de uma parte denominada Lyon-Perrache, que corresponde ao espaço situado entre a estação de Perrache e a Praça Bellecour. A edição de I9I3 e as seguintes, até a de I928, não apresentam mais nenhuma organização por bairros. Somente um itinerário é proposto, o que parte da Praça Terreaux "para aqui retornar" 53 , com indicações bem definidas do percurso a seguir.

Quanto aos guias POL, estes adotam estrutura bastante similar, com uma separação em várias seções. A edição I909 do Guide pratique de Lyon et de sa région é assim dividido em partes numeradas: I) De Perrache até Bellecour; 2) De Bellecour até Terreaux; 3) Fourvière, Saint-Jean, Saint-Paul; 4) Passeio sobre o rio Saône: Perrache, Bellecour, Vaise e Ile Barbe; 5) Guillotière; 6) Brotteaux, Parc de la Tête d’Or; 7) Croix-Rousse, Martinière; 8) Saint-Just e Saint-Irénée. Cada seção contém uma planta parcial da cidade com o traçado do itinerário de visita correpondente. A edição de I94I retoma a mesma organização, com exceção da parte destinada ao passeio sobre o Rio Saône, que foi suprimida.

\section{INFORMAÇõES ESPACIAIS E O SIG - SISTEMA DE INFORMAÇõES GEOGRÁFICAS}

No nosso conhecimento, não existem ainda pesquisas em língua francesa sobre a literatura turística do século XX que contemple a utilização de SIG para tratar e cruzar os dados espaciais extraídos dos guias. Não obstante, o guia de viagem impresso apresenta um forte potencial de estudo no que diz respeito à representação do espaço urbano. Cada um dos três materiais que compõem o guia (texto, ilustrações, mapas) contém informações úteis do ponto de vista espacial.

\section{Texto}

O texto possui inúmeras informações com referência espacial: rios, edifícios, praças, ruas, parques, fontes, bairros, colinas. O levantamento sistemático dessas citações textuais torna possível a geolocalização no SIG das entidades espaciais nomeadas.

52 MONMARCHÉ, Marcel (Dir.). Lyon et ses environs. Paris: Hachette, I944, p. 72-74.

53 Syndicat d'initiative de Lyon. Lyon-Pittoresque, I9I3, p. I9. 
Assim, é possível, para cada edição, espacializar os pontos de interesse, os itinerários, os pontos de vista e os panoramas recomendados e também a divisão do espaço urbano no guia. A fim de possibilitar o tratamento correto dos dados textuais, é necessário dispor o texto no formato digital (TXT) para cada edição do corpus. Os guias encontrados em meio eletrônico e aqueles que digitalizamos estão disponíveis no formato PDF. O texto é convertido para o formato numérico por um programa de reconhecimento óptico de caracteres (OCR), necessitando em seguida de uma fase de verificação e correção. Esse processo de transcrição numérica dos dados textuais é longo, mas abre numerosas possibilidades de análise e de tratamento.

\section{Ilustrações}

A maioria das ilustrações apresentadas nos guias são perspectivas urbanas, principalmente fotografias. É possível geolocalizar com precisão os locais onde foram realizadas tais imagens no SIG. O mapeamento desses pontos de vista permite colocar em evidência os espaços que são frequentemente valorizados pelas ilustrações turísticas e compará-los, por exemplo, com o mapeamento dos panoramas recomendados no texto. Podemos, em seguida, melhorar a precisão das informações associadas às imagens: ângulo de visão, distinção das diferentes perspectivas...

\section{Mapas}

As plantas urbanas contêm também informações que podem ser integradas no SIG. Podemos assim traçar a extensão espacial de cada planta (figura 4), espacializar os elementos presentes na legenda do mapa, as edificações mais importantes e os pontos de interesse. 


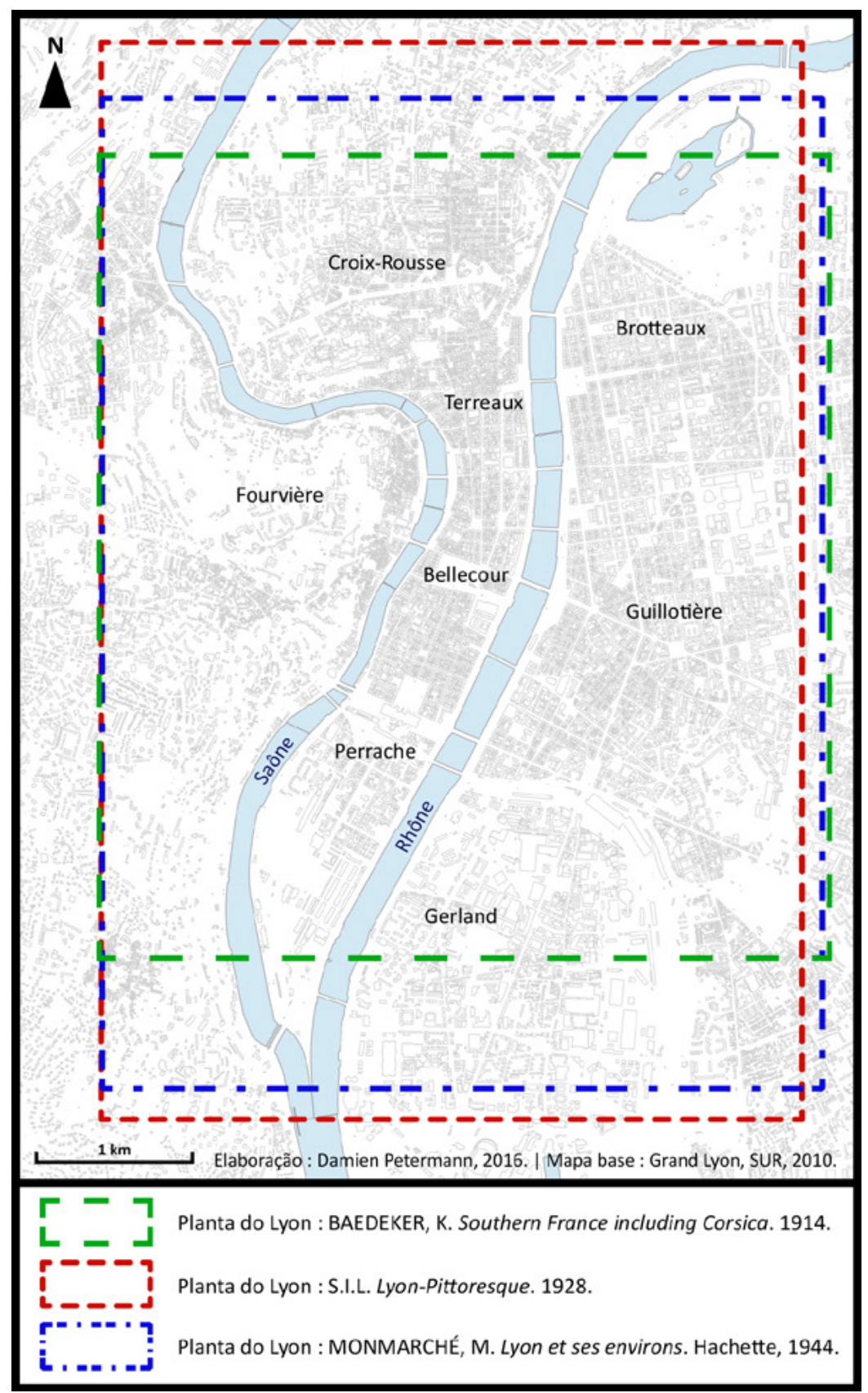

Figura 4-Comparação da extensão espacial de algumas plantas de guias

Esse material apresenta, no entanto, alguns obstáculos que tornam difíceis sua digitalização e seu estudo. Em geral a planta é anexada ao guia por uma pequena faixa de papel, no final do volume ou entre duas páginas. É preciso desdobrá-la para poder proceder à consulta. Em razão da sua fragilidade, o material cartográfico 
está frequentemente ausente nos exemplares físicos consultados em bibliotecas ${ }^{54}$. Quando presente, uma parte da planta pode estar ausente ou rasgada, em função de uma utilização inadequada. A digitalização correta das plantas intactas também é complicada. Na biblioteca ou nos arquivos, muitas vezes é necessário se contentar com fotografias para não danificar o documento. As plantas são, em muitos casos, de grandes dimensões e, como são fixadas no guia, é difícil estabilizá-las na horizontal a fim de tirar uma fotografia de qualidade. A digitalização das plantas em guias comprados ou emprestados por colecionadores particulares é outra operação bastante delicada. É necessário todo o cuidado no momento da manipulação do documento a fim de não danificá-lo. A dificuldade consiste em manter a planta na horizontal, sobre o vidro do scanner, tendo o guia ao lado, a fim de não rasgá-la. Pudemos digitalizar corretamente algumas plantas dos guias do corpus ${ }^{55}$, no entanto, como se trata de plantas dobráveis, existem marcas de dobraduras na imagem digitalizada.

\section{Um exemplo de tratamento: o traçado dos itinerários de visita}

Os itinerários de visita recomendados podem ser explícitos ou implícitos. A partir da edição de I929, o folheto-guia do SIL contém uma planta da cidade com o traçado dos quatro itinerários propostos ${ }^{5}$. Todos os percursos partem da Praça Bellecour: o primeiro é dedicado à visita ao sul da Presqu'île; o segundo leva até a colina da Croix-Rousse; o terceiro passa sobre a margem direita do Rio Saône (Fourvière, Saint-Jean, Saint-Paul, Saint-Just, Saint-Irénée); e o quarto promove a visita à margem esquerda do Rhône (parque da Tête-d'Or, Brotteaux, Prefeitura, Guillotière e Universidade). Após ter levantado os percursos na planta, pudemos espacializar no SIG os quatro itinerários recomendados no guia do SIL de I929 (figura 5).

54 HANCOCK, Claire, 2003, op. cit, p. 69.

55 Agradecemos a Patrick Desfarges e Julie Erismann, que nos possibilitaram utilizar o scanner da Maison de

l’Orient et de la Méditerranée de Lyon para digitalizar algumas plantas de grandes dimensões.

56 Syndicat d’initiative de Lyon. Lyon - Guide officiel illustré. Paris: Mayeux, I929, p. I6-I7. 


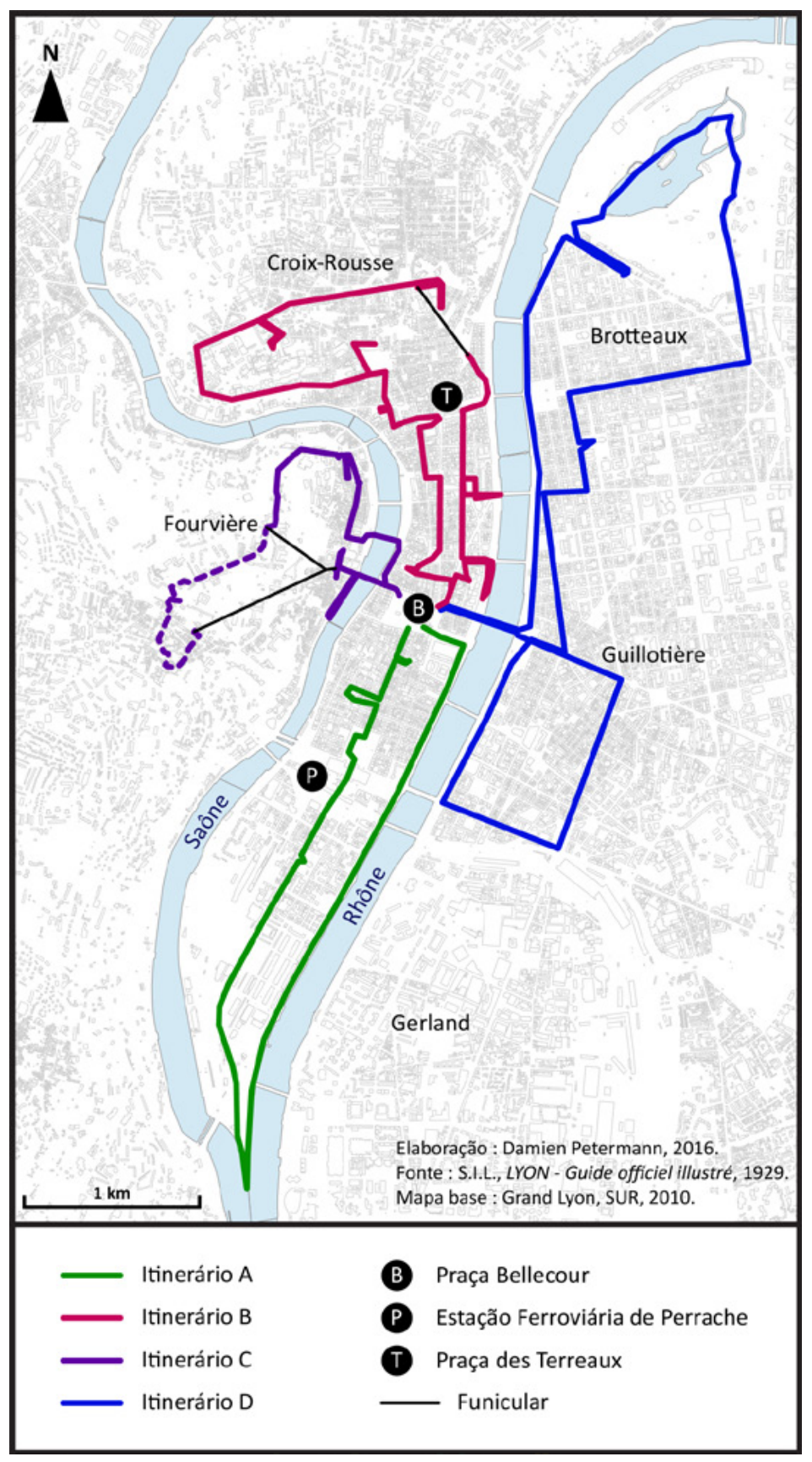

Figura 5 - A espacialização no SIG dos quatro itinerários recomendados no guia do SIL de I929 


\section{CONCLUSÃo E PERSPECTIVAS DE ESTUdO}

O guia de viagem impresso é uma fonte que apresenta grande interesse no estudo da evolução da imagem da cidade. Até o presente, esse tipo de fonte foi pouco estudado por pesquisadores de língua francesa. A abordagem geo-histórica é particularmente adaptada à análise dos guias de viagem. A evolução das representações espaciais de Lyon pode ser acompanhada pela busca e identificação precisas das mudanças no discurso turístico, principalmente identificando as entradas e saídas de objetos de uma edição a outra.

A integração e a análise num SIG dos dados espaciais extraídos dos guias podem levar a resultados bastante interessantes. $O$ objetivo é constituir, para cada material (texto, ilustração, planta), para cada edição estudada e para o conjunto do corpus, o mapeamento do espaço efetivamente entregue ao olhar do viajante e, em oposição, de espaços urbanos que não aparecem nos guias. O estudo dessas fontes no SIG tem também o interesse de poder confrontar a visão turística do espaço urbano a uma topografia verificada, ao espaço real da cidade. Por outro lado, os dados espaciais extraídos dos guias são compatíveis com as camadas vetoriais realizadas durante o projeto USP-Cofecub, pois o mapeamento de referência utilizado é o sistema urbano de referência de Lyon (SUR) ${ }^{57}$.

\section{Apêndice I - Lista dos guias de viagem reunidos no corpus de estudo}

- I90I

- BAEDEKER, Karl. Le Sud-Est de la France du Jura à la Méditerranée et y compris la Corse. 7. ed. Leipzig: Karl Baedeker; Paris: Paul Ollendorff, I90I.

- 1902

- BAEDEKER, Karl. Southern France including Corsica. 4. ed. Leipzig: Karl Baedeker, I9O2.

- JOANNE, Paul. Bourgogne, Morvan, Jura, Lyonnais. Paris: Hachette, I902.

- Syndicat d'initiative de Lyon. Lyon-Pittoresque. Lyon, I902.

- 1903

- Syndicat d'initiative de Lyon. Lyon-Pittoresque. Lyon, I903.

- 1905

- PAILLON, Maurice. Lyon et ses environs. Paris: Hachette, I905.

- 1906

- BAEDEKER, Karl. Le Sud-Est de la France du Jura à la Méditerranée y compris la Corse. 8. ed. Leipzig: Karl Baedeker; Paris: Paul Ollendorff, I906.

- BAEDEKER, Karl. Die Riviera, das südöstliche Frankreich, Korsika, die Kurorte in Südtirol, an den oberitalienischen Seen und am Genfer See. 4. ed. Leipzig: Karl Baedeker, I906.

- Lyon et ses environs. Paris: Hachette, I906.

- Syndicat d'initiative de Lyon. Lyon-Pittoresque. Lyon, I906. 
- I907

- BAEDEKER, Karl. Southern France including Corsica. 5. ed. Leipzig: Karl Baedeker e Londres: T. Fischer Unwin, I907.

- JOANNE, Paul. Bourgogne, Morvan, Jura, Lyonnais. Paris: Hachette, I907.

- Syndicat d'initiative de Lyon. Lyon-Pittoresque. Lyon, I907.

- 1908

- Syndicat d’initiative de Lyon. Lyon-Pittoresque. Lyon, I908.

- I909

- TOURSIER Gustave. Guide pratique de Lyon et de sa région. Lyon: Société des Guides POL, I909.

- I9I0

- BAEDEKER, Karl. Le Sud-Est de la France du Jura à la Méditerranée y compris la Corse. 9. ed. Leipzig: Karl Baedeker; Paris: Paul Ollendorff, I9Io.

- I9I3

- BAEDEKER, Karl. Die Riviera, das südöstliche Frankreich, Korsika, die Kurorte in Südtirol, an den oberitalienischen Seen und am Genfer See. 5. ed. Leipzig: Karl Baedeker, I9I3.

- Syndicat d'initiative de Lyon. Lyon-Pittoresque. Lyon, I9I3.

- TOURSIER, Gustave (Dir.). Guide pratique de Lyon et de sa région. Lyon: Société des Guides POL, [I9I3?].

- I9I4

- BAEDEKER, Karl. Southern France including Corsica. 6. ed. Leipzig: Karl Baedeker e Londres: T. Fischer Unwin, I9I4.

- Lyon et ses environs. Paris : Hachette, I9I4.

- I920

- MONMARCHÉ, Marcel (Dir.). Bourgogne, Franche-Comté, Morvan, Jura, Lyonnais. Paris: Hachette, I920.

- MONMARCHÉ, Marcel (Dir.). De Paris aux Alpes et à la Méditerranée, Réseau PLM. Paris: Hachette; Londres: Macmillan, I920.

- 1922

- TOURSIER, Gustave (Dir.). Guide pratique de Lyon et de sa région. II. ed. Lyon: Société des Guides POL, [I922?].

- 1923

- MONMARCHÉ, Marcel (Dir.). Vallée du Rhône, Cévennes, Lyonnais, Velay, Vivarais, Gorges du Tarn. Paris: Hachette, I923.

- MONMARCHÉ, Marcel (Dir.). France en 4 volumes. Sud-est: le réseau PLM. Paris: Hachette, I923.

- 1925

- Lyon et ses environs. Paris: Hachette, I925.

- 1928

- Syndicat d'initiative de Lyon. Lyon-Pittoresque. Lyon, I928.

- 1929

- Syndicat d'initiative de Lyon. LYON - Guide officiel illustré. Paris: Mayeux, I929. 
- I930

- BAEDEKER, Karl. Riviera, südöstliches Frankreich, Korsika, oberitalienische Seen, Meran, Genfer See. 6. ed. Leipzig: Karl Baedeker, I930.

- Syndicat d'initiative de Lyon. LYON - Guide officiel illustré. Paris: Mayeux, I930.

- TOURSIER, Gustave (Dir.). Guide pratique de Lyon et de sa région. I5. ed. Lyon: Société des Guides POL, I930-I93I.

- I93I

- MONMARCHÉ, Georges; LECOMPTE-BOINET, J. Bourgogne, Franche-Comté, Jura, Lyonnais. Paris: Hachette, I93I.

- Syndicat d'initiative de Lyon. LYON - Guide officiel illustré. Paris: Mayeux, I93I.

- 1932

- Lyon et ses environs. Paris: Hachette, I932.

- 1933

- Bourgogne, Jura, Lyonnais. Paris: Hachette, I933.

- I935

- Syndicat d'initiative de Lyon. LYON - Guide officiel illustré. Paris: Mayeux, I935.

- 1938

- MONMARCHÉ, Marcel (Dir.). France automobile en un volume. Paris: Hachette, I938.

- Syndicat d'initiative de Lyon. LYON - Guide officiel illustré. Paris: Mayeux, I938.

- 1939

- MONMARCHÉ, Georges (Dir.). Bourgogne, Morvan, Nivernais, Lyonnais, Paris: Hachette, I939.

- BEAUVAIS, Gaston. Vosges-Jura, Champagne, Lorraine, Alsace, Bourgogne, Lyonnais, Franche-Comté. Paris: Hachette, I939.

- I94I

- BÉRERD, Francis (Dir.). Guide pratique de Lyon et de sa région. I5. ed. Lyon: Société des Guides POL, I94I.

- I944

- MONMARCHÉ, Marcel (Dir.). Lyon et ses environs. Paris: Hachette, I944.

- 1947

- MONMARCHÉ, Georges (Dir.). France automobile en un volume. Paris: Hachette, I947.

\section{SOBRE O AUTOR}

DAMIEN PETERMANN é doutorando em Geografia na Université de Lyon, Université Jean Moulin - Lyon 3. UMR 5600 Environnement Ville Société.

E-mail: damien.petermann@yahoo.fr 


\section{REFERÊNCIAS BIBLIOGRÁFICAS}

BAEDEKER, Karl. Die Riviera, das südöstliche Frankreich, Korsika, die Kurorte an den oberitalienischen Seen und am Genfer See. I. ed. Leipzig: Karl Baedeker, I898.

. Le Sud-Est de la France du Jura à la Méditerranée y compris la Corse. 8. ed. Leipzig: Karl Baedeker; Paris: Paul Ollendorff, I906.

. Southern France including Corsica. 6. ed. Leipzig: Karl Baedeker; Londres: T. Fischer Unwin, I9I4.

BERTRAND, Gilles. Le Grand Tour Le Grand Tour revisité. Pour une archéologie du tourisme: le voyage des Français en Italie, milieu XVIIIe siècle-début XIXe siècle). Rome: École Française de Rome. Collection de l'Ecole Française de Rome, n. 398, 2008, 79I p.

BRANDT, Susanne. Le voyage aux champs de bataille. Vingtième siècle, revue d'histoire, n. 4I, janvier-mars I994, p. I8-22. Disponível em: <www.persee.fr/doc/xxs_0294-I759_I994_num_4I_I_3262〉. Acesso em: out. 2016.

CHABAUD, Gilles; MONZANI, Pierre. Les guides de Paris aux XVII et XVIII siècles, images de la ville. Dissertação (Mestrado em História). Université Paris I, I979.

CHABAUD, Gilles et al. (Dir.). Les guides imprimés du XVI au XXe siècle. Villes, paysages, voyages. Colloque I998, Université Paris VII. Paris: Belin, 2000.

COHEN, Évelyne; VAJDA, Joanne, TOULIER, Bernard (Dir.). Le patrimoine des guides: lectures de l'espace urbain européen. In Situ, n. I5, 20II. Disponível em: 〈http://insitu.revues.org/III . Acesso em: out. 2016

CRÉATION d'un Syndicat d'initiative dans l'intérêt de la Ville de Lyon et ses environs, I90I, 4 p., Lyon, Musées Gadagne, inv. I895.8.

DAMIEN, Elsa. La notion de guide à l'épreuve du tourisme naissant. Les voyageurs anglo-saxons en Italie à l'ère industriell. Tese (Doutorado em Estudos Italianos). Université Paris III, Sorbonne Nouvelle, 2004.

DEVANTHÉRY, Ariane. Itinéraires. Les guides de voyage en Suisse de la fin du XVIII siècle à I9I4. Pour une histoire culturelle du tourisme. Tese (Doutorado em Literatura). Université de Lausanne, 2008.

FRANCON, Marc. Le Guide Vert Michelin. L'invention du tourisme culturel populaire. Paris: Economica, 2001.

GEIGER, Wolfgang. Chapitre X. Regards croisés sur la France I940-I944. In: GEIGER, Wolfgang. L’image de la France dans l'Allemagne nazie: I933-I945. Rennes: Presses Universitaires de Rennes, I999, \$242. Disponível em: 〈http://books.openedition.org/pur/9296〉. Acesso em: out. 2016.

GORDON, Bertram M. Ist Gott Französisch? Germans, tourism, and occupied France, I940-I944. Modern ercontemporary France, 4:3, I996, p. 287-298.

HANCOCK, Claire. Paris et Londres au XIX siècle. Représentations dans les guides et récits de voyage. Paris: CNRS éditions, 2003.

HARP, Stephen L. Touring the trenches. Michelin Guides to World War I Battlefields. In: Marketing Michelin: advertising \& cultural identity in twentieth-century France. Baltimore and London: J. Hopkins University Press, 200I, p. 89-I25.

HINRICHSEN, Alex W. Baedeker's Reisehandbücher, I832-I99 - Bibliographie I832-I944: Verzeichnis I948I990: Verlagsgeschichte mit Abbildungen und zusätzlichen Übersichten. 2. ed. Bevern: U. Hinrichsen, I99I.

HUBÉ, Nicolas; CHUPIN, Ivan; KACIAF, Nicolas. Histoire politique et économique des médias en France. Paris: La Découverte, 2009.

IMEC - Institut Mémoires de l'Édition Contemporaine. Les collections. Hachette Livre. Disponível em: <www.imec-archives.com/fonds/hachette-livre . Acesso em: out. 2016 
JOURNAL Officiel de la République Française. Lois et décrets, I3 mars I92I, année 53, n. 7I, p. 3.I59-3.I60. Disponível em: 〈http://gallica.bnf.fr/ark:/I2I48/bpt6k64394I7f.r〉. Acesso em: out. 2016.

LES GUIDES DE PARIS (les historiens d'art et les corpus numériques), dirigido por Marianne Cojannot-Leblanc (Labex Les Passés dans le Présent), em parceria com a Bibliothèque Nationale de France. Disponível em: 〈http://www.passes-present.eu/fr/node/363〉. Acesso em: out. 2016.

MONMARCHÉ, Marcel (Dir.). Bourgogne, Franche-Comté, Morvan, Jura, Lyonnais. Paris: Hachette, I920. (Dir.). Lyon et ses environs. Paris: Hachette, I944, p. 72-74. (Dir.). France automobile en un volume. Paris: Hachette, I947, p. VIII-X.

MORLIER, Hélène. Les Guides-Joanne, Genèse des Guides-Bleus. Paris: Les Sentiers débattus, 2007.

PAILLON, Maurice. Lyon et ses environs. Paris: Hachette, I905.

PETERMANN, Damien. L'espace lyonnais représenté à l'usage des voyageurs aux époques moderne et contemporaine, histoire et construction de l'image d'un territoire, XVII ${ }^{-} \mathrm{XX}{ }^{e}$ siècles, sob a orientação do professor Bernard Gauthiez, Université Jean Moulin Lyon 3 (co-diretor: Gilles Bertrand, Université Pierre Mendès France Grenoble 2). Esta tese é financiada pela Região Rhône-Alpes (ARC 7).

PRIVAT-SAVIGNY, Maria-Anne (Dir.). Lyon, centre du monde! L'exposition internationale urbaine de I9I4. Catálogo da exposição. Lyon: Musées Gadagne, 2013.

RECLUS, Onésime. À la France, Sites et monuments. Paris: Touring Club de France, I900-I906. 32 v. Disponível em: 〈http://catalogue.bnf.fr/ark:/I2I48/cb3II856I4w >. Acesso em : out. 2016.

SANTANA, Nara Maria Carlos de (Org.). Turismo entre diálogos. Interpretações sobre gestão, política, cultura e sociedade. Rio de Janeiro: Faperj/e-papers, 2012.

SAUNIER, Pierre-Yves. Lyon au XIX ${ }^{e}$ siècle: les espaces d'une cité. I992. Tese (Doutorado em História). Université Lumière Lyon 2, I992.

SEOANE, Annabelle. Les mécanismes énonciatifs dans les guides touristiques: entre genre et positionnements discursifs. Paris: L’Harmattan, 2013.

SYNDICAT d'initiative de Lyon. Lyon-Touriste. $\mathrm{I}^{\mathrm{er}}$ mars I906, I ${ }^{\mathrm{re}}$ année, n. 3, p. 5.

. Lyon-Touriste. $\mathrm{I}^{\mathrm{er}}$ septembre I906, $\mathrm{I}^{\mathrm{re}}$ année, n. 9, p. I.

. Lyon-Touriste. $\mathrm{I}^{\mathrm{er}}$ mars I907, $2^{\mathrm{e}}$ année, n. 3, p. 2.

. Lyon-Touriste. $\mathrm{I}^{\mathrm{er}}$ août I907, $2^{\mathrm{e}}$ année, n. 8, p. 2.

. Lyon-Touriste. $\mathrm{I}^{\mathrm{er}}$ mars $1908,3^{\mathrm{e}}$ année, n. 3, p. 4 .

. Lyon-Touriste. $\mathrm{I}^{\mathrm{er}}$ janvier I909, $4^{\mathrm{e}}$ année, n. I, p. 3.

. Lyon-Pittoresque. I9I3, p. I9.

. Lyon - Guide officiel illustré. Paris: Mayeux, I929, p. I6-I7.

TOURING CLUB de France. Revue mensuelle. Disponível em: <http://gallica.bnf.fr/ark:/22I48/cb34350057f/ date $\geq$. Acesso em: out. 2016.

. La France en images. 2 albums, I922. Disponível em Gallica: Ière série: 〈http://gallica.bnf.fr/ ark:/I2I48/btvibI050877Is.r> et 2e série: 〈http://gallica.bnf.fr/ark:/I2I48/btvibI0508829p.r〉.

TOURSIER, Gustave (Dir.). Guide pratique de Lyon et de sa région. II. ed. Lyon: Société des Guides POL [I922?].

UNITED STATES. Army Service Forces, Information and Education Division. Pocket guide to the cities of Southern France. Washington DC, I944, VI-82 p. Disponível em: <https://archive.org/details/PocketGuideToTheCitiesOfSouthernFrance >. Acesso em: out. 2016. 